\title{
PERAN BRAND AWARENESS DALAM MEMEDIASI PENGARUH DAYA TARIK IKLAN TERHADAP NIAT BELI
}

\author{
Dewa Ayu Diah Paramita Dewi ${ }^{1}$ \\ I Made Jatra ${ }^{2}$ \\ ${ }^{1,2}$ Fakultas Ekonomi dan Bisnis Universitas Udayana, Bali, Indonesia \\ e-mail: diahprmtd@gmail.com
}

\begin{abstract}
ABSTRAK
Penelitian ini bertujuan untuk mengetahui pengaruh daya tarik iklan dan brand awareness terhadap niat beli, serta peran brand awareness dalam memediasi pengaruh daya tarik iklan terhadap niat beli, studi dilakukan pada produk smartphone merek Vivo di Kota Denpasar. Penelitian ini menggunakan ukuran sampel berjumlah 100 orang, melalui metode penentuan sampel purposive sampling. Pengumpulan data dilakukan dengan penyebaran kuisioner yang diukur dengan 12 indikator dan menggunakan skala likert. Teknik analisis yang digunakan adalah analisis jalur (path analysis) dan disertai dengan uji sobel. Hasil dari penelitian ini menunjukan bahwa daya tarik iklan berpengaruh positif dan signifikan terhadap brand awareness. Daya tarik iklan berpengaruh positif dan signifikan terhadap niat beli, brand awareness berpengaruh positif dan signifikan terhadap niat beli. Penelitian ini juga membuktikan bahwa brand awareness mampu memediasi hubungan antaran pengaruh daya tarik iklan terhadap niat beli.
\end{abstract}

Kata kunci: daya tarik iklan, brand awareness, niat beli

\begin{abstract}
Study aims to determine the effect of advertising attractiveness and brand awareness on buying intentions, as well as the role of brand awareness in mediating the effect of advertising attractiveness on purchasing intentions, a study conducted on Vivo brand smartphone products in Denpasar City. This research was using sample size amounted to 100 people, through purposive sampling method. Data collection was done by distributing questionnaires measured by 12 indicators and using Likert scale. The analytical technique used is path analysis and a sobel test. Results of this study showed that the attractiveness of advertising has a positive and significant impact on brand awareness. The attractiveness of advertising has a positive and significant impact on purchasing intentions, brand awareness has a positive and significant impact on purchasing intentions. This study also proves that brand awareness is able to mediate the relationship between the effects of advertising attractiveness on buying intentions.
\end{abstract}

Keywords: ad attractiveness, brand awareness, purchase interest 
Dewa Ayu Diah Paramita Dewi, Peran Brand Awarnessdalam Memediasi...

\section{PENDAHULUAN}

Perkembangan teknologi merupakan hal yang penting di jaman globalisasi seperti sekarang ini, terutama teknologi komunikasi dan informasi. Di era global ini, manusia memiliki mobilitas yang sangat tinggi, sehingga dituntut untuk bergerak cepat dan berpikir maju. Teknologi komunikasi dan informasipun berkembang begitu pesat, salah satu perangkat komunikasi dan informasi yang berkembang yaitu telepon pintar atau smartphone. Menurut Williamset et al. (2011) smartphone adalah telepon selular dengan mikroprosesor, memori, layar dan modem bawaan. Smartphone merupakan ponsel multimedia yang menggabungkan fungsionalitas perangkat Computer atau PC dan handset sehingga menghasilkan gadget yang mewah, dimana terdapat pesan teks, kamera, pemutar musik, video, game, akses email, televisi (tv) digital, search engine, pengelola informasi pribadi, fitur GPS (Global Positioning System), jasa telepon internet dan bahkan terdapat telepon yang juga berfungsi sebagai kartu kredit.

Tabel 1 menyajikan jumlah pengguna smartphone di Indonesia dari tahun 2013 hingga 2017. Tabel menunjukan pengguna smartphone di Indonesia meningkat setiap tahunnya, dikutip dari halaman katadata.co.id yang bersumber pada Emarketer.

Tabel 1.

Pengguna Smartphone di Indonesia Tahun 2013 - 2017

\begin{tabular}{lccccc}
\hline Keterangan & $\mathbf{2 0 1 3}$ & $\begin{array}{c}\text { Tahun } \\
\mathbf{2 0 1 4} \\
\text { (juta) }\end{array}$ & $\begin{array}{c}\mathbf{2 0 1 5} \\
\text { (juta) }\end{array}$ & $\begin{array}{c}\mathbf{2 0 1 6} \\
\text { (juta) }\end{array}$ & $\begin{array}{c}\mathbf{2 0 1 7} \\
\text { (juta) }\end{array}$ \\
\hline (juta) \\
\hline Pengguna (orang) & 27,4 & 38,3 & 52,2 & 65,2 & 74,9 \\
Pertumbuhan (\%) & & 28,46 & 26,63 & 19,94 & 12,95 \\
\hline Sumber: Emarketer, Oktober 2017 & & & &
\end{tabular}


Tabel 1 menunjukan jumlah pengguna smartphone di Indonesia meningkat dari tahun ke tahun, dari tahun 2013 ke tahun 2014 menunjukan peningkatan sebesar 28,46\%, pada tahun 2014 ke tahun 2015 meningkat 26,63\%, kemudian dari tahun 2015 ke tahun 2016 mengalami peningkatan sebesar 19,94\%, kemudian dari tahun 2016 ke tahun 2017 mengalami pertumbuhan sebesar 12,95\%. Emarketer juga memproyeksikan pengguna smartphone di Indonesia akan meningkat sebesar 25 juta pengguna hingga tahun 2019. Data tersebut memberikan peluang yang cukup besar untuk produsen smartphone memasarkan produknya di Indonesia. Meningkatnya pengguna smartphone di Indonesia membuat produsen smartphone bersaing menawarkan produknya. Produsen berlomba-lomba mengembangkan diferensiasi produk smartphone yang di keluarkan untuk menarik minat konsumen. Salah satu produsen smartphone yaitu Vivo.

Vivo adalah perusahaan elektronik yang didirikan pada tahun 2009 di Dongguan, Guangdong, Tiongkok. Vivo merupakan salah sartu anak perusahaan BBK Electronics. Namun mereka baru mencuat pada tahun 2012. Vivo sendiri masuk ke pasar Asia Tenggara, termasuk Indonesia pada tahun 2014.

Tabel 2.

Data Pangsa Pasar Smartphone di Dunia (\%)

\begin{tabular}{ccccccc}
\hline Period & Samsung & Apple & Huawei & OPPO & Vivo & Others \\
\hline 2016Q1 & 23,8 & 15,4 & 8,4 & 5,9 & 4,4 & 42,1 \\
2016Q2 & 22,7 & 11,7 & 9,3 & 6,6 & 4,8 & 45,0 \\
2016Q3 & 20,9 & 12,5 & 9,3 & 7,1 & 5,9 & 44,3 \\
2016Q4 & 18,0 & 18,2 & 10,5 & 7,3 & 5,7 & 40,2 \\
2017Q1 & 23,3 & 14,7 & 10,0 & 7,5 & 5,5 & 39,0 \\
\hline
\end{tabular}

Tabel 2 menyajikan data market share 5 perusahaan smartphone. Tabel International Data Corporation (IDC) menunjukan smartphone merek Samsung 
masih menguasai pangsa pasar global, di peringkat kedua yaitu smartphone merek Apple, dan di peringkat berikutnya di tempati oleh smartphone produksi perusahaan asal China yaitu Huawei, Oppo dan Vivo. Ketiga smartphone asal China ini memperoleh pangsa pasar dengan total 23\% pada tahun 2017 kuartal pertama. Dibandingkan dengan pendahulunya yaitu Huawei dan Oppo, pangsa pasar Vivo yang tergolong pendatang baru sudah hamper menyamai persentase pangsa pasar Oppo. Vivo mengalami peningkatan market share ditahun 2016 pada kuartal pertama ke kuartal kedua sebesar $0,4 \%$, kemudian meningkat kembali pada kuartal ketiga sebesar $0,9 \%$ tetapi mengalami penurunan pada kuartal keempat dan kelima, masing-masing sebesar 0,2\%. Data IDC tersebut mengindikasikan sudah munculnya kesadaran merek (brand awareness) dari produk smartphone merek Vivo.

Banyak cara yang digunakan oleh Vivo untuk meningkatkan brand awareness, karena jika melihat produk smartphone ini terhitung baru dalam persaingan dengan vendor smartphone merek lain yang sudah terlebih dahulu memasuki persaingan global dan juga jika mengacu pada tabel 2 yang menunjukan penurunan market share, cara yang digunakan Vivo adalah dengan beriklan. Perusahaan smartphone merek Vivo merangkul FIFA sebagai sponsor resmi gelaran Piala Dunia 2018 di Rusia. Seperti dikutip dari Forbes dalam tirto.id, Vivo diperkirakan mengeluarkan dana sebesar 60 juta Euro pada FIFA untuk ajang sepak bola dunia tersebut. Strategi Vivo menjadi sponsor resmi Piala Dunia tentu saja agar produknya dikenal dunia. Sebagaimana dikutip dari The Verge, Piala Dunia adalah gelaran yang selalu dinanti dan dilihat banyak orang. 
Pada Piala Dunia 2014 di Brasil, sebanyak 3,2 miliar orang menonton pertandingan selama sebulan. Pada pertandingan final, disaksikan lebih dari satu miliar orang. Selain itu di Indonesia Vivo juga beriklan pada televisi, media sosial dan media cetak dengan menggandeng beberapa artis ternama, beberapa diantaranya adalah Agnes Monica, Afgan, Pevita Pearce, dan Al Ghazali. Strategi beriklan ini digunakan oleh Vivo untuk menambah daya tarik pada iklannya secara rasional maupun emosional, yang kemudian diharapkan meningkatkan brand awareness terhadap produknya, sehingga memunculkan niat beli dari konsumen. Berdasarkan survei awal yang peneliti lakukan terhadap 20 orang responden di Kota Denpasar yang belum pernah menggunakan smartphone merek Vivo, 17 orang atau $85 \%$ responden menjawab menyadari dan mengetahui produk smartphone merek Vivo karena iklan yang mereka lihat, sedangkan 3 orang responden atau $15 \%$ menyatakan tidak menyadari dan mengetahui produk smartphone merek Vivo. 15 orang atau $75 \%$ responden menyatakan iklan smartphone merek Vivo menarik dan 5 orang atau $25 \%$ responden menyatakan iklan smartphone merek Vivo tidak menarik. Jadi hasil prasurvei tersebut menyatakan bahwa brand awareness smartphone merek Vivo sudah cukup tinggi dengan iklan menarik yang ditayangkan, namun jika dibandingkan dengan smartphone merek lain seperti Oppo, Huawei, Apple dan Samsung, brand awareness dari smartphone merek Vivo ini masih tergolong rendah dan masih harus ditingkatkan kembali.

Kesadaran Merek (brand awareness) merupakan kemampuan konsumen untuk mengenali atau mengingat kembali suatu merek ketika berpikir mengenai 
Dewa Ayu Diah Paramita Dewi, Peran Brand Awarnessdalam Memediasi...

suatu kategori produk tertentu dan terdapat kemudahan saat namatersebut dimunculkan (Shimp, 2014:97). Herdana (2015) menyatakan bahwa, brand awareness adalah kesanggupan masyarakat sebagai calon pembeli untuk mengenali dan mengingat keberadaan merek di pikiran mereka sendiri. Meningkatkan brand awareness adalah salah satu cara dalam mengembangkan pangsa pasar dari suatu merek (Agusli dan Kunto, 2013).

Shah et al. (2012) menyatakan bahwa, brand awareness memiliki empat peranan utama yaitu: menjadi sumber asosiasi lain, menimbulkan rasa suka atau familiar, sumber komitmen terhadap merek, dan menjadi bahan pertimbangan untuk menggunakan merek. Hsin et al. (2009) menyatakan bahwa munculnya nama merek tertentu di benak konsumen ketika hendak membeli suatu produk, mengindikasikan produk tersebut memiliki kesadaran merek yang tinggi. Chi et al. (2009), menyatakan bahwa brand awareness berpengaruh signifikan terhadap niat beli, hal yang sama juga disampaikan oleh Agusli dan Kunto (2013), yang menyatakan bahwa brand awareness merupakan salah satu alasan alasan konsumen untuk membeli suatu produk yang didasarkan hasil identifikasi atas suatu merek produk, semakin tinggi tingkatan brand awareness yang dimiliki suatu produk, maka semakin tinggi pula niat konsumen untuk melakukan pembelian terhadap produk tersebut. Menurut Tulasi (2012) iklan memengaruhi brand awareness secara positif dan signifikan. Dari beberapa stategi yang digunakan untuk membangun sebuah brand awareness, strategi yang paling sering digunakan yaitu iklan yang merupakan salah satu bagian dari bauran pemasaran. 
Bauran promosi merupakan gabungan dari beberapa strategi untuk memperkenalkan sebuah produk. Pada dasarnya promosi dilakukan untuk memperkenalkan produk kepada konsumen dan konsumen menyadari keberadaan produk tersebut. Tjiptono (2011) pada hakikatnya promosi adalah suatu bentuk komunikasi pemasaran. Komunikasi pemasaran adalah aktivitas pemasaran yang berusaha menyebarkan informasi, mempengaruhi/membujuk, dan atau mengingatkan pasar sasaran atas perusahaan dan produknya agar bersedia menerima, membeli, dan loyal pada produk yang ditawarkan perusahaan yang bersangkutan. Hariadi (2013) promosi adalah salah satu variabel di dalam bauran pemasaran yang sangat penting dilaksanakan oleh perusahaan dalam pemasaran produknya. Promosi merupakan salah satu faktor penentu keberhasilan suatu program pemasaran. Bagaimanapun kualitasnya suatu produk, bila konsumen belum pernah mendengarnya dan tidak yakin bahwa produk itu akan berguna bagi mereka, maka mereka tidak akan pernah membelinya. Selain itu, komunikasi pemasaran mempunyai andil dalam ekuitas merek bagi perusahaan (Kotler \& Keller, 2009: 174).

Iklan merupakan salah satu alat pemasaran yang digunakan untuk memengaruhi konsumen untuk menyadari keberadaan suatu merek (Gunawan dan Dharmayanti, 2014). Variabel iklan dapat diartikan segala bentuk penyajian dan promosi ide, barang atau jasa secara non personal yang dilakukan oleh perusahaan sponsor tertentu. Iklan juga berfungsi untuk memengaruhi konsumen agar memahami dan sadar dengan merek yang akan dan telah menjadi pilihannya. Iklan dapat digunakan untuk membangun citra jangka panjang dan mampu 
Dewa Ayu Diah Paramita Dewi, Peran Brand Awarnessdalam Memediasi...

menjangkau calon konsumen walau letaknya berjauhan, sehingga iklan merupakan cara yang efektif untuk menyebarkan pesan atau informasi suatu merek kepada konsumen. Marhadi dkk. (2014) menyatakan iklan yang efektif adalah iklan yang memiliki daya tarik, yaitu kemampuan untuk menarik perhatian pasar sasaran. Daya Tarik dalam suatu iklan adalah pesan penjualan yang paling persuasif yang ditujukan untuk menarik perhatian konsumen. Menurut Bulbul dan Menon (2010), daya tarik iklan digunakan untuk memengaruhi perasaan, membujuk, serta mempertahankan gambaran produk di benak konsumen.

Menurut penelitian Sawant (2012), menyatakan iklan berpengaruh positif dan signifikan terhadap brand awareness. Penelitian serupa juga diungkapkan oleh Wuryandari (2014), yang menyatakan seluruh bagian dari promotion mix termasuk iklan berpengaruh positif dan signifikan terhadap niat beli. Kemudian Chi et al. (2009) menyatakan bahwa brand awareness berpengaruh positif dan signifikan terhadap niat beli. Hasil yang bertentangan dikemukakan oleh Keke (2015), yang menyatakan bahwa iklan tidak berpengaruh dengan brand awareness.

Penelitian mengenai brand awareness yang memediasi pengaruh daya tarik iklan terhadap niat beli pada konsumen smartphone merek Vivo ini sangat menarik untuk di teliti. Dilihat dari prasurvei yang menyatakan sudah banyak yang sadar dengan keberadaan smartphone merek Vivo melalui iklan menarik yang ditayangkan, dan penguasaan pangsa pasar yang cukup tinggi untuk produk smartphone yang tergolong baru tetapi jika dibandingkan dengan pesaingnya seperti Oppo, Huawei, Apple dan Samsung, brand awareness smartphone merek 
Vivo masih tergolong rendah. Pengaruh daya tarik iklan diharapkan lebih dapat meningkatkan brand awareness dari produk smartphone merek Vivo ini.Adanya research gap, seperti yang dikemukakan oleh Keke (2015), yaitu iklan tidak berpengaruh signifikan terhadap brand awareness konsumen, kemudian penelitian yang dilakukan oleh Susilo dan Samuel (2015) menyatakan bahwa brand awareness berpengaruh positif terhadap niat beli tetapi tidak signifikan, mendorong penulis untuk melakukan penelitian lebih lanjut.

Iklan dapat membentuk kesadaran merek terhadap suatu produk. Menurut Sawant (2012) yang melakukan penelitian pada produk pakaian menyatakan bahwa iklan berpengaruh positif dan signifikan terhadap brand awareness, hal serupa juga disampaikan oleh Tulasi (2012), semua elemen pada promotion mix (termasuk iklan di dalamnya) mempengaruhi secara positif dan signifikan terhadap brand awareness. Hal selaras juga disampaikan oleh Gunawan dan Dharmayanti (2014) yang mengemukakan bahwa iklan sebagai media promosi terbukti memiliki hubungan positif dan signifikan serta berperan penting dalam peningkatan brand awareness.

Ndela dan Chucu (2016) juga mendapatkan hasil yang sama, dalam penelitiannya mengenai iklan dengan celebrity endorsement terhadap brand awareness dan purchase behavior. Peneliatn tersebut menunjukan iklan dengan daya tarik pendukung berpengaruh positif dan sgnifikan terhadap brand awareness. Hal yang sama juga di sampaikan oleh Grigaliunaite dan Pileliene (2016) melalui hasil penelitiannya yang menyatakan daya tarik rasional maupun 
Dewa Ayu Diah Paramita Dewi, Peran Brand Awarnessdalam Memediasi...

emosional dalam iklan mampu mempengaruhi brand awareness. Berdasarkan penelitian tersebut dapat di tentukan hipotesis sebagai berikut:

$\mathrm{H}_{1}$ : Daya tarik iklan berpengaruh positif dan signifikan terhadap brand awareness.

Wuryandari (2014), menyatakan bahwa seluruh bagian dari promotion mixberpengaruh positif dan signifikan terhadap niat beli. Hal serupa juga dikemukakan oleh Arista dan Astuti (2011), yaitu iklan berpengaruh positif dan signifikan terhadap niat beli. Pernyataan tersebut diperkuat oleh penelitian Muthohar dan Triatmaja (2013) dalam penelitiannya juga menyatakan bahwa endorser yang digunakan dalam iklan dan iklan itu sendiri dapat meningkatkan niat beli secara positif dan signifikan.

Lin (2011) dalam penelitiannya menyatakan adanya pengaruh positif dan signifikan antara daya tarik iklan terhadap niat beli, daya tarik rasional lebih dominan daripada daya tarik emosional dalam kaitannya dengan niat pembelian produk high involment seperti telepon seluler. Berdasarkan penjelasan tersebut dapat ditentukan hipotesis sebagai berikut:

$\mathrm{H}_{2}$ : Daya tarik iklan berpengaruh positif dan signifikan terhadap niat beli.

Shah et al. (2012) menyatakan bahwa brand awareness berpengaruh positif dan signifikan terhadap niat beli. Hasil penelitian Chi et al. (2009) mengemukakan bahwa semakin tinggi brand awareness, maka semakin tinggi pula niat beli, jadi brand awareness berpengaruh secara positif dan signifikan terhadap niat beli. Malik et al. (2013) juga menyatakan bahwa brand awareness berpengaruh positif signifikan terhadap niat beli. Berdasarkan uraian tersebut dapat ditentukan hipotesis sebagai berikut: 
$\mathrm{H}_{3}$ : Brand awareness berpengaruh positif dan signifikan terhadap niat beli.

Penelitian Tulasi (2012) menyatakan bahwa semua elemen promotion mix termasuk iklan di dalamnya dapat berpengaruh positif dan signifikan terhadap brand awareness. Chi et al. (2009) mengemukakan bahwa semakin tinggi brand awareness, maka semakin tinggi pula niat beli, jadi brand awareness berpengaruh secara positif dan signifikan terhadap niat beli. Muthohar dan Triatmaja (2013) dalam penelitiannya juga menyatakan bahwa endorser yang digunakan dalam iklan dan iklan itu sendiri dapat meningkatkan niat beli secara positif dan signifikan. Yudhiartika dan Haryanto (2012) secara tidak langsung menyatakan bahwa brand awareness mampu memediasi pengaruh iklan dan niat beli. Penelitian serupa dilakukan oleh Gunawan dan Dharmayanti (2014) yang secara tidak langsung menyatakan brand awareness mampu memediasi iklan dengan daya tarik pendukungnya atau endorser terhadap niat beli. Berdasarkan penjelasan tersebut dapat ditentukan hipotesis sebagai berikut:

$\mathrm{H}_{4}$ : Brand awareness secara signifikan memediasi pengaruh daya tarik iklan terhadap niat beli.

\section{METODE PENELITIAN}

Penelitian ini menggunakan pendekatan kuantitatif berbentuk asosiatif. Menurut Rahyuda dkk. (2004:17) pendekatan asosiatif merupakan pendekatan yang bertujuan untuk mengetahui hubungan dua variabel atau lebih. Pendekatan ini digunakan karena bertujuan untuk mengetahui pengaruh daya tarik iklan terhadap brand awareness, pengaruh brand awreness terhadap niat beli, serta 
peran mediasi brand awareness dalam pengaruh daya tarik iklan terhadap niat beli.

Penelitian ini dilakukan di Kota Denpasar, karena Kota Denpasar yang terdiri dari empat kecamatan, dan memiliki jumlah penduduk 636.599 orang pada tahun 2016 (denpasarkota.go.id), merupakan kota berpenduduk heterogen yang berasal dari berbagai daerah lain di Provinsi Bali akibat urbanisasi. Denpasar merupakan pusat bisnis dan pendidikan yang penduduknya memiliki mobilitas yang tinggi, sehingga smartphone sudah menjadi kebutuhan bagi penduduk Kota Denpasar.objek dalam penelitian ini adalah perilaku konsumen khususnya niat beli konsumen yang tumbuh akibat brand awareness dan pengaruh iklan mengenai produk smartphone merek Vivo.

Variabel bebas dalam penelitian ini adalah daya tarik iklan yang disimbulkan dengan X. Daya tarik iklan adalah pesan yang terdapat pada periklanan yang digunakan untuk membujuk, memengaruhi dan membuat gambaran pada benak konsumen mengenai produk smartphone merek Vivo dan mempengaruhi perilaku konsumen.

Variabel mediasi pada penelitian ini adalah brand awareness yang disimbulkan dengan $\mathrm{Y}_{1}$. Brand Awareness didefinisikan sebagai kemampuan konsumen mengingat kembali merek smartphone Vivo yang merupakan bagian dari kategori produk smartphone.

Variabel terikat dalam penelitian ini adalah niat beli yang disimbolkan dengan $\mathrm{Y}_{2}$. Niat beli didefinisikan sebagai perilaku konsumen yang telah 
mempelajari lebih jauh mengenai produk smartphone Vivo yang kemudian memunculkan keinginan untuk membeli produk tersebut.

Rahyuda dkk. (2004:41) populasi adalah jumlah keseluruhan dari unit analisis yang ciri-cirinya akan diduga. Populasi yang digunakan pada penelitian ini adalah masyarakat kota Denpasar yang belum pernah menggunakan produk smartphone Vivo dan berniat membeli smartphone Vivo, dengan jumlah yang tidak diketahui secara pasti (infinite). Sampel adalah bagian dari jumlah dan karakteristik yang dimiliki oleh populasi tersebut. Sampel yang diambil dari populasi harus benar-benar representatif (Sugiyono, 2017:85). Ukuran sampel terbaik yang disarankan untuk mengukur multivariate adalah $5-10$ observasi setiap parameter yang diestimasi (Sugiyono, 2013:130). Penelitian ini menggunakan 12 indikator sehingga dengan menggunakan estimasi berdasarkan jumlah parameter diperoleh ukuran sampel sebesar 60-120 responden. Ukuran sampel yang digunakan dalam penelitian ini adalah 100 responden.Metode pengumpulan sampel non probability sampling dengan teknik purposive samplingdigunakan pada penelitian ini. Teknik ini merupakan teknik pengumpulan sampel yang menentukan sampel dengan pertimbangan tertentu (Sugiyono, 2017:85).

Penelitian ini menggunakan metode survei sebagai metode pengumpulan data dengan menggunakan kuisioner. Kuisioner berisi seperangkat pertanyaan tertulis yang bersifat tertutup atau terbuka yang diserahkan secara langsung kepada responden untuk dijawab (Rahyuda dkk., 2004:80). Kuisioner terdiri dari pernyataan terbuka yang berisikan data diri responden dan pernyataan tertutup 
yang berisikan pertanyaan dan pernyataan responden. Pernyataan tertutup diukur menggunakan skala likert dengan skala 1 sampai 5. Kuesioner disebarkan secara langsung di toko-toko handphone di Kota Denpasar dan online.

Data kualitatif dalam penelitian ini adalah jenis kelamin responden, pendidikan terakhir responden, dan pekerjaan responden. Data kuantitatif dalam penelitian ini berupa jumlah pengguna smartphone di Indonesia dari tahun 2013 sampai 2017 yang bersumber dari emarketer, jumlah responden, dan hasil penilaian responden terhadap pernyataan kuesioner.

Data primer dalam penelitian ini adalah responden yang memberikan penilaian atas pernyataan yang terdapat dalam kuesioner mengenai variabelvariabel dalam penelitian. Data sekunder dalam penelitian ini adalah institusi atau pihak terkait yang mempublikasikan data yang dikutip terkait dengan topik penelitian, seperti emarketer, International Data Corporation dan denpasarkota.go.id.

Statistik inferensial adalah teknik statistik yang digunakan untuk menganalisis data sampel dan hasilnya diberlakukan untuk populasi (Sugiyono, 2016:170). Statistik inferensial digunakan untuk menjawab hipotesis. Dalam penelitian ini, statistik inferensial yang digunakan adalah analisis jalur dan uji sobel.

Teknik analisis yang digunakan dalam penelitian ini adalah teknik analsis jalur (path analysis). Ghozali (2013:249) mendefinisikan analisis jalur (path analysis) adalah perluasan dari analisis regresi linear berganda dalam memperkirakan hubungan kausalitas antara variabel yang telah ditetapkan 
sebelumnya berdasarkan teori. Analisis jalur digunakan untuk menentukan pola hubungan antara tiga atau lebih dan tidak dapat digunakan untuk mengkonfirmasi atau menolak hipotesis. Ridwan dan Kuncoro (2011:2) menyatakan analisis jalur digunakan untuk menganalisis pola hubungan antar variabel dengan tujuan untuk mengetahui pengaruh langsung maupun tidak langsung seperangkat variabel independen terhadap variabel dependen. Dasar perhitungan koefisien jalur adalah analisis korelasi dan regresi dan dalam perhitungan menggunakan software dengan program SPSS for windows.

Persamaan Sub-struktural 1

$$
\mathrm{Y}_{1}=\beta_{1} \mathrm{X}+\mathrm{e}_{1}
$$

Persamaan Sub-struktural 2

$$
\mathrm{Y}_{2}=\beta_{2} \mathrm{X}+\beta_{3} \mathrm{Y}_{1}+\mathrm{e}_{2}
$$

Keterangan :

$\mathrm{Y}_{2} \quad=$ niat beli

$\mathrm{X} \quad=$ daya tarik iklan

$\mathrm{Y}_{1} \quad=$ brand awareness

$\beta_{1}, \beta_{2}, \beta_{3}=$ koefisien regresi variabel

e $\quad=$ error

\section{HASIL DAN PEMBAHASAN}

Hipotesis daya tarik iklan $(\mathrm{X})$ berpengaruh terhadap brand awareness $\left(\mathrm{Y}_{1}\right)$ akan dibahas dengan persamaan struktur I.

Hipotesis electronic word of mouth (X) berpengaruh terhadap niat beli (Y) akan dibahas dengan persamaan struktur II.

Persamaan struktur I, dapat disusun berdasarkan hasil pelaporan analisis regresi I sebagai berikut : 
Hasil pelaporan analisis regresi I

$$
\begin{array}{ll}
\mathrm{Y}_{1} & =0,761 \mathrm{X} \\
\mathrm{Se} & =0,062 \\
\mathrm{~T} & =11,607 \\
\text { Sig } & =0,000 \\
\mathrm{R}^{2} & =0,579 \\
\mathrm{~F} & =134,724
\end{array}
$$

Dari pelaporan regresi I dapat ditulis persamaan struktur I, yaitu sebagai berikut :

$$
\mathrm{Y}_{1}=0,761 \mathrm{X}
$$

Persamaan struktural II, didapat dari hasil analisis regresi II, yang dilaporkan sebagai berikut :

Hasil pelaporan analisis regresi II

$$
\begin{array}{ll}
\mathrm{Y}_{2} & =0,409+0,504 \\
\mathrm{Se} & =(0,102) \quad(0,108) \\
\mathrm{T} & =(5,085) \quad(6,271) \\
\text { Sig } \mathrm{F} & =0,000 \\
\mathrm{R}^{2} & =0,736 \\
\mathrm{~F} & =135,016
\end{array}
$$

Dari pelaporan regresi II dapat ditulis persamaan struktur II, yaitu sebagai berikut :

$\mathrm{Y}_{2}=0,409 \mathrm{X}+0,504 \mathrm{M}$

Tabel 3.

Hasil Uji Normalitas Persamaan Regresi 1

\begin{tabular}{lc}
\hline & Unstandardized Residual \\
\hline $\mathrm{N}$ & 100 \\
Kolmogorov-Smirnov & 0,679 \\
Asymp. Sig. (2-tailed) & 0,747 \\
\hline
\end{tabular}

Sumber:data primer diolah, 2018

Berdasarkan data yang disajikan pada Tabel 3 dapat dilihat bahwa nilai Kolmogorov-Smirnov sebesar 0,679 dan nilai Asymp. Sig. (2-tailed) sebesar 0,747. Hasil tersebut mengindikasikan bahwa model persamaan regresi tersebut 
berdistribusi normal karena nilai Asymp. Sig. (2-tailed) lebih besar dari taraf signifikansi yang ditetapkan yaitu 5 persen $(0,05)$.

Tabel 4.

Hasil Uji Normalitas Persamaan Regresi 2

\begin{tabular}{lc}
\hline & Unstandardized Residual \\
\hline $\mathrm{N}$ & 100 \\
Kolmogorov-Smirnov & 0,942 \\
Asymp. Sig. (2-tailed) & 0,337 \\
\hline Sumber. data primer diolat
\end{tabular}

Sumber: data primer diolah, 2018

Berdasarkan data yang disajikan pada Tabel 4 dapat dilihat bahwa nilai Kolmogorov-Smirnov sebesar 0,942 dan nilai Asymp. Sig. (2-tailed) sebesar 0,337. Hasil tersebut mengindikasikan bahwa model persamaan regresi tersebut berdistribusi normal karena nilai Asymp. Sig. (2-tailed) lebih besar dari taraf signifikansi yang ditetapkan yaitu 5 persen $(0,05)$.

Tabel 5.

Hasil Uji Multikolinearitas Persamaan Regresi 2

\begin{tabular}{|c|c|c|}
\hline \multirow{2}{*}{ Model } & \multicolumn{2}{|c|}{ Collinearity Statistics } \\
\hline & Tolerance & $V I F$ \\
\hline Daya Tarik Iklan & 0,421 & 2,375 \\
\hline Brand Awareness & 0,421 & 2,375 \\
\hline
\end{tabular}

Sumber:data primer diolah, 2018

Berdasarkan data pada Tabel 5 dapat dilihat bahwa koefisien tolerance sebesar 0,421 yang berarti koefisien tolerance lebih besar dari 0,10 dan VIF sebesar 2,375 lebih kecil dari 10. Hal ini berarti bahwa tidak terdapat gejala multikolinieritas dari model regresi yang dibuat dan otomatis tidak adanya korelasi antara variabel eksogen yang digunakan, sehingga model ini layak digunakan untuk memprediksi. 
Tabel 6.

Hasil Uji Heteroskedastisitas Persamaan Regresi 2

\begin{tabular}{cc} 
Model & Sig.t \\
\hline Daya Tarik Iklan & 0,579 \\
Brand Awareness & 0,264 \\
\hline
\end{tabular}

Sumber:data primer diolah, 2018

Berdasarkan data pada Tabel 6 dapat dilihat bahwa nilai Sig.t variabel daya tarik iklan sebesar 0,579 dan variabel kepercayaan sebesar 0,264. Nilai tersebut lebih besar dari 0,05 yang mengandung arti bahwa tidak terdapat pengaruh antara variabel eksogen terhadap absolute residual. Dengan demikian model yang dibuat bebas dari gejala heteroskedastisitas.

Berdasarkan model substruktural 1 dan model substruktural 2, maka dapat disusun model diagram jalur akhir. Sebelum menyusun model diagram jalur akhir, terlebuh dahulu dihitung nilai standar error sebagai berikut:

$$
\begin{aligned}
& \mathrm{e}_{1}=\sqrt{1-R 1^{2}}=\sqrt{1-0,579}=0,649 \\
& \mathrm{e}_{2}=\sqrt{1-R 2^{2}}=\sqrt{1-0,736}=0,514
\end{aligned}
$$

Berdasarkan perhitungan pengaruh error $\left(\mathrm{e}_{1}\right)$ sebesar 0,649 dan pengaruh error $\left(\mathrm{e}_{2}\right)$ sebesar 0,514

Hasil koefisien determinasi total adalah sebagai berikut:

$$
\begin{aligned}
\mathrm{R}^{2} \mathrm{~m} & =1-\left(\mathrm{Pe}_{1}\right)^{2}\left(\mathrm{Pe}_{2}\right)^{2} \\
& =1-(0,649)^{2}(0,514)^{2} \\
& =1-(0,421)(0,264) \\
& =1-0,111 \\
& =0,889
\end{aligned}
$$

Nilai determinasi total sebesar 0,889 mempunyai arti bahwa sebesar 88,9 persen variasi niat beli dipengaruhi oleh variasi daya tarik iklan dan variasi brand awareness, sementara sisanya sebesar 11,1 persen dijelaskan oleh faktor lain yang tidak dimasukkan ke dalam model. 
Berdasarkan hasil pengujian yang telah dilakukan, diperoleh tingkat signifikansi $\mathrm{F}$ sebesar $0,000<0,05$, yang berarti variabel daya tarik iklan dan variabel brand awareness berepengaruh secara simultan terhadap variabel niat beli. Jadi model persamaan struktural telah memenuhi syarat Goodness of Fit melalui uji F.

Berdasarkan hasil uji hubungan daya tarik iklan terhadap brand awareness, diperoleh hasil sig.t sebesar 0,000 dengan nilai beta sebesar 0,761. Berdasarkan pada nilai sig. t yang menunjukan nilai $0,000<0,05$, maka dapat diartikan bahwa $\mathrm{H}_{0}$ di tolak dan $\mathrm{H}_{1}$ diterima, jadi dapat dijelaskan bahwa daya tarik iklan berpengaruh positif dan signifikan terhadap brand awareness.

Berdasarkan hasil uji hubungan daya tarik iklan terhadap niat beli, diperoleh hasil sig.t sebesar 0,000 dengan nilai beta sebesar 0,409. Berdasarkan pada nilai sig. $\mathrm{t}$ yang menunjukan nilai $0,000<0,05$, maka dapat diartikan bahwa $\mathrm{H}_{0}$ di tolak dan $\mathrm{H}_{1}$ diterima, jadi dapat dijelaskan bahwa daya tarik iklan berpengaruh positif dan signifikan terhadap niat beli.

Berdasarkan hasil uji hubungan brand awareness terhadap niat beli, diperoleh hasil sig.t sebesar 0,000 dengan nilai beta sebesar 0,504. Berdasarkan pada nilai sig. $\mathrm{t}$ yang menunjukan nilai $0,000<0,05$, maka dapat diartikan bahwa $\mathrm{H}_{0}$ di tolak dan $\mathrm{H}_{1}$ diterima, jadi dapat dijelaskan bahwa brand awareness berpengaruh positif dan signifikan terhadap niat beli. 
Tabel 7.

Pengaruh Langsung, Pengaruh Tidak Langsung dan Pengaruh Total Daya Tarik Iklan (X), Brand Awareness $\left(\mathrm{Y}_{1}\right)$ dan Niat Beli $\left(\mathbf{Y}_{2}\right)$

\begin{tabular}{cccc}
\hline $\begin{array}{c}\text { Pengaruh } \\
\text { Variabel }\end{array}$ & $\begin{array}{c}\text { Pengaruh } \\
\text { Langsung }\end{array}$ & $\begin{array}{c}\text { Pengaruh Tidak } \\
\text { Langsung melalui } \\
\text { Brand Awareness } \\
(\mathbf{Y 1})=(\boldsymbol{\beta} 1 \mathbf{x} \boldsymbol{\beta 3})\end{array}$ & Pengaruh Total \\
\hline $\mathrm{X} \rightarrow \mathrm{Y}_{1}$ & 0,761 & - & 0,761 \\
$\mathrm{X} \rightarrow \mathrm{Y}_{2}$ & 0,409 & 0,311 & 0,720 \\
$\mathrm{Y}_{1} \rightarrow \mathrm{Y}_{2}$ & 0,504 & - & 0,504 \\
\hline
\end{tabular}

Sumber: data primer diolah, 2018

Hasil yang disajikan pada tabel 7 menunjukan bahwa, pengaruh langsung variabel daya tarik iklan terhadap niat beli memiliki nilai koefisien beta sebesar 0,409, sedangkan pengaruh tidak langsung yang dimediasi oleh brand awareness menunjukkan nilai koefisiem beta sebesar 0,311. Hasil tersebut membuktikan bahwa brand awareness memediasi hubungan daya tarik iklan terhadap niat beli dengan pengaruh total yang diperoleh sebesar 0,720 .

Uji Sobel merupakan alat analisis untuk menguji signifikansi hubungan tidak langsung antara variabel bebas dengan terikat yang dimediasi oleh variabel yang berperan sebagai mediator. Pada penelitian ini, uji sobel digunakan untuk mengetahui pengaruh variabel brand awareness dalam memediasi hubungan antara pengaruh variabel daya tarik konsumen dan variabel niat beli pada produk smartphone merek Vivo. Uji sobel dirumuskan dengan persamaan berikut dan dapat dihitung dengan menggunakan aplikasi Microsoft Excel. Bila nilai kalkulasi $\mathrm{Z}$ lebih besar dari 1,96(dengan tingkat kepercayaan 95 persen), maka variabel mediasi dinilai secara signifikan memediasi hubungan antara variabel bebas dan variabel terikat.

$$
\mathrm{Z}=\frac{a b}{\sqrt{b^{2} S a^{2}+a^{2} S b^{2}+S a^{2} S b^{2}}}
$$


Keterangan:
$\begin{array}{ll}\mathrm{a} & =0,761 \\ \mathrm{~b} & =0,504 \\ \mathrm{Sa} & =0,062 \\ \mathrm{Sb} & =0,108\end{array}$

$Z=\frac{(0,761) \cdot(0,504)}{\sqrt{(0,504)^{2} \cdot(0,062)^{2}+(0,761)^{2} \cdot(0,108)^{2}+(0,062)^{2} \cdot(0,108)^{2}}}$

$Z=\frac{(0,3835)}{\sqrt{(0,0068)+(0,0010)+(0,0000)}}$

$\mathrm{Z}=4,3494$

Berdasarkan perhitungan yang telah dilakukan tersebut, diperoleh nilai $\mathrm{Z}$ sebesar 4,3494> 1,96. Hasil ini menyatakan variabel mediasi yaitu brand awareness dinilai dapat memediasi pengaruh daya tarik iklan terhadap niat beli produk smartphone merek Vivo di Kota Denpasar.

Penelitian ini memiliki beberapa tujuan, salah satunya yaitu mengetahui pengaruh daya tarik iklan terhadap brand awareness. Menurut hasil olah data yang telah dilakukan, diperoleh koefisien beta sebesar 0,761, dengan tingkat signifikansi sebesar 0,000 $(\leq 0,05)$, Hipotesis pertama diterima. Hasil tersebut memiliki arti daya tarik iklan berpengaruh positif dan signifikan terhadap brand awareness produk smartphone merek Vivo. Jadi dapat dijelaskan bahwa semakin tinggi daya tarik iklan, maka semakin meningkat brand awareness dariproduk smartphone merek Vivo.Hasil penelitian ini memperkuat penelitian sebelumnya yang dilakukan oleh Sawant (2012), Tulasi (2012), Gunawan dan Dharmayanti (2014) yang mengemukakan bahwa iklan sebagai media promosi terbukti memiliki hubungan positif dan signifikan serta berperan penting dalam peningkatan brand awareness. Ndela dan Chucu (2016) juga mendapatkan hasil 
iklan dengan daya tarik pendukung berpengaruh positif dan signifikan terhadap brand awareness. Hal yang sama juga di sampaikan oleh Grigaliunaite dan Pileliene (2016) melalui hasil penelitiannya yang menyatakan daya tarik rasional maupun emosional dalam iklan mampu mempengaruhi brand awareness

Tujuan selanjutnya yaitu mengetahui pengaruh daya tarik iklan terhadap niat beli. Menurut hasil olah data yang telah dilakukan, diperoleh koefisien beta sebesar 0,409, dengan tingkat signifikansi sebesar 0,000 $(\leq 0,05)$, Hipotesis kedua diterima. Hasil tersebut memiliki arti daya tarik iklan berpengaruh positif dan signifikan terhadap niat beli produk smartphone merek Vivo. Jadi dapat dijelaskan bahwa semakin tinggi daya tarik yang dihasilkan oleh iklan produk smartphone merek Vivo, maka semakin tinggi pula menimbulkan niat beli konsumen pada produk smartphone merek Vivo.Hasil penelitian ini memperkuat penelitian sebelumnya yang dilakukan oleh Wuryandari (2014), Arista dan Astuti (2011), Muthohar dan Triatmaja (2013) dalam penelitiannya menyatakan iklan berpengaruh positif dan signifikan terhadap niat beli. Kemudian Lin (2011) dalam penelitiannya menyatakan adanya pengaruh positif dan signifikan antara daya tarik iklan terhadap niat beli.

Tujuan selanjutnya yaitu mengetahui pengaruh brand awareness terhadap niat beli. Menurut hasil olah data yang telah dilakukan, diperoleh koefisien beta sebesar 0,504, dengan tingkat signifikansi sebesar 0,000 $(\leq 0,05)$, Hipotesis ketigaditerima. Hasil tersebut memiliki arti brand awareness berpengaruh positif dan signifikan terhadap niat beli produk smartphone merek Vivo. Jadi dapat dijelaskan bahwa semakin tinggi brand awareness produk smartphone merek 
Vivo, maka semakin tinggi pula menimbulkan niat beli konsumen pada produk smartphone merek Vivo.Hasil penelitian ini memperkuat penelitian sebelumnya yang dilakukan oleh Shah et al. (2012), Chi et al. (2009), Malik et al. (2013) juga menyatakan bahwa brand awareness berpengaruh positif signifikan terhadap niat beli.

Telah dijelaskan bahwa daya tarik iklan memiliki pengaruh secara parsial pada variabel brand awareness, dan brand awareness memiliki pengaruh secara parsial pada variabel niat beli. Penelitian ini dilakukan untuk mengetahui peran brand awareness dalam memediasi pengaruh daya tarik iklan terhadap niat beli. Pengujian pertama menggunakan uji sobel dimana memperoleh hasil angka $\mathrm{Z}=$ 4,3494> 1,96. Hasil ini memberikan arti bahwa variabel mediasi yaitu brand awareness memberikan pengaruh pada hubungan variabel daya tarik iklan terhadap niat beli. Melihat dari hasil olah data yang tertera pada Tabel 7 menunjukkan bahwa terdapat nilai pengaruh secara tidak langsung sebesar 0,311, hasil ini memberikan arti bahwa brand awareness dapat memediasi pengaruh daya tarik iklan terhadap niat beli, selain itu hasil penelitian juga menunjukkan nilai pengaruh langsung brand awareness terhadap niat beli tidak sama dengan nol $(0,504 \neq 0)$, sehingga dapat diketahui bahwa variabel brand awareness memediasi secara parsial. Hasil di atas memberikan arti bahwa hipotesis keempat yang menyatakan brand awareness dapat memediasi pengaruh daya tarik iklan terhadap niat beli pada konsumen yang belum pernah membeli smartphone merek Vivo dapat diterima. Hasil ini berarti bahwa semakin tinggi daya tarik yang dihasilkan oleh iklan smartphone merek Vivo, semakin tinggi pula brand 
awareness dari smartphone merek Vivo itu sendiri, dan brand awareness ini akan menimbukan niat beli pada konsumen.

Yudhiartika dan Haryanto (2012) secara tidak langsung menyatakan bahwa brand awareness mampu memediasi pengaruh iklan dan niat beli. Penelitian serupa dilakukan oleh Gunawan dan Dharmayanti (2014) yang secara tidak langsung menyatakan brand awareness mampu memediasi iklan dengan daya tarik pendukungnya atau endorser terhadap niat beli.

\section{Implikasi dan Keterbatasan Penelitian}

Implikasi teoretis pada penelitian ini berkaitan mengenai niat beli yang memperkuat penelitian sebelumnya bahwa daya tarik iklan dan brand awareness mampu memengaruhi niat konsumen untuk membeli suatu produk. Selain itu brand awareness dinilai dapat memediasi pengaruh daya tarik iklan terhadap niat beli suatu produk. Semakin tinggi daya tarik iklan suatu produk, maka akan meningkatkan brand awareness dari produk tersebut. Dengan meningkatnya brand awareness suatu produk menjadi salah satu peran yang penting untuk meningkatkan niat konsumen untuk membeli suatu produk. Jika brand awareness rendah, maka niat konsumen untuk membeli suatu produkpun akan rendah.Penelitian ini diharapkan menjadi sesuatu yang baru untuk penelitian mengenai daya tarik iklan, brand awareness dan niat beli.

Pada penelitian ini juga memiliki beberapa keterbatasan, antara lain yaitu penelitian dilakukan hanya terbatas di Kota Denpasar jadi tidak dapat digeneralisasi ke daerah lainnya, waktu dan biaya yang sangat terbatas sedangkan strategi pemasaran mengalami perubahan yang sangat cepat 


\section{SIMPULAN DAN SARAN}

Berdasarkan pembahasan dan hasil penelitian yang telah dilakukan, maka dapat ditarik beberapa simpulkan bahwa daya tarik iklan berpengaruh positif dan signifikan terhadap brand awareness. Pernyataan ini berarti semakin tinggi daya tarik dari iklan suatu produk, maka semakin tinggi pula brand awareness terhadap produk tersebut.Daya tarik iklan berpengaruh positif dan signifikan terhadap niat beli. Pernyataan ini berarti semakin tinggi daya tarik dari iklan suatu produk, maka semakin tinggi niat konsumen untuk membeli produk tersebut.Brand awareness berpengaruh positif dan signifikan terhadap niat beli. Pernyataan ini berarti semakin tinggi kesadaran konsumen terhadap suatu merek, maka semakin tinggi pula niat konsumen untuk membeli produk tersebut.

Brand awareness secara signifikan dapat memediasi pengaruh daya tarik iklan terhadap niat beli. Pernyataan ini berarti bahwa brand awareness dapat menjembatani pengaruh daya tarik iklan terhadap niat beli. Dapat dijelaskan bahwa semakin tinggi daya tarik iklan makan akan membuat semakin tinggi pula brand awareness dari suatu produk, hal ini akan meningkatkan niat konsumen untuk membeli produk. Mediasi yang terjadi bersifat parsial. Karena bersifat parsial, apabila tanpa brand awareness, daya tarik iklan tetap mampu berpengaruh positif dan signifikan terhadap niat beli.

Setelah penelitian ini dilakukan dan diperoleh hasil dan pembahasan, makan dapat diberikan beberapa saran, yaitu dalam penelitian ini daya tarik iklan di ukur menggunakan empat indikator, dari keempat indikator, daya tarik rasional 
mendapatkan nilai rata-rata terendah. Dengan begitu produsen smartphone merek Vivo diharapkan dapat memperbaiki kualitas dan mencantumkan lebih banyak lagi informasi mengenai kualitas produk sehingga dapat menarik minat konsumen untuk membeli produk smartphone merek Vivo. Variabel selanjutnya yaitu brand awareness, diukur menggunakan empat indikator, merek yang mudah diingat memperoleh nilai rata-rata terendah. Dengan begitu diharapkan untuk produsen smartphone merek Vivo dapat membuat ciri khas, bisa melalui iklan ataupun spesifikasi untuk smartphone merek Vivo, sehingga konsumen dapat dengan mudah mengingat Vivo sebagai salah satu merek smartphone. Variabel terakhir yaitu niat beli, diukur menggunakan empat indikator, ingin membeli produk menjadi indikator dengan nilai rata-rata terendah, dengan demikian diharapkan untuk produsen smartphone merek Vivo diharapkan lebih gencar lagi melakukan promosi salah satunya dengan beriklan, dengan begitu akan dapat meningkatkan niat konsumen untuk membeli produk smartphone merek Vivo dapat meningkat.

\section{REFERENSI}

Agusli, Devonalita., dan Yohanes Sondang Kunto. 2013. Analisis Pengaruh Dimensi Ekuitas Merek Terhadap Minat Beli Konsumen Midtown Hotel Surabaya. Jurnal Manajemen Pemasaran Petral. Vol. 1, No.2, hal.1-8

Arista, E. Desi, dan Sri Rahayu Triastuti. 2011. Analisis Pengaruh Iklan , Kepercayaan Merek, dan Citra Merek terhadap Minat Beli Konsumen. Aset, Vol. 13. No. 1, hal.37-45.

Bulbul, Cenk, dan Menon, Geeta. 2010. The Power of Emotional Appeals in Advertising: The Influence of Concrete Versus Abstract Affect on TimeDependent Decisions. Journal of Advertising Research. 10(1), pp: 169:180.

Chi, Hsin Kuang, Huery Ren Yeh dan Ya Ting Yang. 2009. The Impact of Brand Awarness on Consumer Purchase Intention: The Mediating Effect of 
Perceived Quality and Brand Loyality .The Journal of International Management Studies, Vol. 4, No.1, pp:135-144.

Ghozali, Imam. 2013. Aplikasi Analisis Multivariate dengan Program IBM SPSS 2.1, Edisi. Ketujuh, Semarang: Badan Penerbit UNDIP.

Grigaliunaite, Viktorija., dan Pileliene, Lina. 2016. Emotional or Rational? The Determination of The Influence of Advertising Appeal on Advertising Effectiveness. Scientific Annals of Economics and Business, 63(3), pp: 391414.

Gunawan, Fitri Anggraini dan Diah Dharmayanti. 2014. Analisis Pengaruh Iklan Televisi dan Endorser terhadap Purchase Intention Pond's Men dengan Brand Awareness sebagai Variabel Intervening. Jurnal Manajemn Pemasaran Petra, 2(1), hal.1-14.

Hariadi, Doni. 2013. Pengaruh Produk, Harga, Promosi, dan Distribusi Terhadap Keputusan Pembelian Konsumen Pada Produk Microvision. Jurnal Ilmu dan Riset Manajemen.Vol 1 No 1.1 Januari 2013, hal.67-87.

Herdana, Auditya. 2015. Analisis Pengaruh Brand Awareness (Brand Awareness) pada Produk Asuransi Jiwa Prudential Life Assurance (Studi Pada Pru Passion Agency Jakarta). Jurnal Riset Bisnis dan Manajemen, Vol. 3, No.1, hal.1-18.

Hsin, Kuang Chi, dan Ting, Ya Yang.2009. The Impact of Brand Awareness on Cosumer Purcase Intention: The mediating Effect of Perceived Quality dan Brand Loyality. The Journal of InternasionalManagement Studies, 4(1), pp:135-144

Internasional Data Corporation.2017.https://www.idc.com/promo/smartphonemarket-share/vendor. Diakses pada tanggal 15 November 2017.

Katadata.co.id. 2016.katadata.co.id/datapublish/2016/08/08/penggunasmartphone-di-indonesia-2016-2019. Diakses pada tanggal 15 November 2017.

Keke, Yuliati. 2015. Komunikasi Pemasaran Terpadu Terhadap Brand Awareness. Jurnal Manajemen Bisnis Transportasi dan Logistik. Vol. 2, No.1, hal.172186.

Kotler, Philip. dan Armstrong, Garry. 2008. Prinsip-Prinsip Pemasaran. Terjemah oleh Bob Sabran, M.M. Edisi 12. Jakarta: Erlangga.

Kotler, Philip. dan Keller, Kevin Lane. 2009. Manajemen Pemasaran. Jilid 1 Edisi 13. Jakarta: Erlangga. 
Dewa Ayu Diah Paramita Dewi, Peran Brand Awarnessdalam Memediasi...

Lin, Long-Yi. 2011. The Impact of Advertising Appeals and Advertising Spokespersons an Advertising Attitude and Purchase Intentions. African Journal of Business Magement, 5(21), pp: 8446-8457.

Malik, Muhammad Ehsan., Muhammad Mudasar Ghafoor dan Hafiz Khasif Iqbal. 2013. Importance of Brand Awareness and Brand Loyality in Assessing Purchase Intentions of Consumer. International Journal of Business and Social Science, Vol. 4, No. 5, pp: 167-171.

Marhadi., Sulistyowati, L., dan Nursanti, A. 2014. Analisis Pengaruh Kreativitas Iklan, Daya Tarik Iklan dan Kredibilitas Endorser terhadap Brand Attitude pada Produk Handphone Android di Kota Pekanbaru. Jurnal Ekonomi, 22(1), hal.1-19.

Muthohar, Muchsin dan Amin Ramadhan Triatmaja. 2013. Pengaruh Endorser Ulama Terhadap Sikap dan Minat Beli Konsumen (The Influence of Islamic Preacher toward the Attitude and Consumers Purchase Intention). Jurnal Bisnis dan Ekonomi (JBE). Vol. 19, No. 1, hal.86-99.

Ndlela, T., dan Chuchu, T. 2016. Celebrity Endorsement Advertising: Brand Awareness, Brand Recall, Brand Loyalty, as Antecedence of South African Young Consumers' Purchase Behavior. Journal of Economics and Behavioral Studies, 8(2), pp:79-90.

Rahyuda, I K,. I. G. W. Yasa, N. N. Yuliarmi. 2004. Metodologi Penelitian. Diktat Kuliah Fakultas Ekonomi. Denpasar: Universitas Udayana.

Riduwan dan Engkos Achmad Kuncoro.2011. Cara Menggunakan dan Memaknai Analisis Jalur ( Path Analysis ).Bandung : Alfabeta.

Sawant, Roshni. P. 2012. Impact of Advertising on Brand Awareness and Consumer Preference (With Special Reference to Men's Wear). IOSR Journal of Business dan Management, 5(6), pp: 54-61.

Shimp, T. A. 2014. Komunikasi Pemasaran Terpadu dalam Periklanan dan Promosi. Jakarta: Salemba Empat.

Shin, N., Kim H., Lim, S., dan Kim, C. 2014. The Effect of Brand Equity on Brand Attitude and Brand Loyality in Exhibition. EDP Science. 3(12), pp: $1-7$.

Sugiyono, Prof. Dr. 2015. Metode Penelitian Tindakan Komprehensif. Bandung: Alfabeta.

Sugiyono, Prof. Dr. 2016. Metode Penelitian Administrasi. Bandung: Alfabeta.

Sugiyono, Prof. Dr. 2017. Metode Penelitian Administrasi. Bandung: Alfabeta.

Sugiyono. 2013. Metodologi Penelitian Bisnis. Bandung: Alfabeta. 
Susilo, Irine dan Hatane Samuel. 2015. Analisis Pengaruh Emotional Marketing Terhadap Purcase Intention Melalui Brand Awareness pada Produk Dove Personal Care Di Surabaya. Jurnal Manajemen Pemasaran. Vol. 9, No.1, hal.23-34

Tjiptono, Fandy. 2011. Manajemen \& Strategi Merek. Yogyakarta: Andi.

Tulasi, Dominikus. 2012. Marketing Communication dan Brand Awareness. Humaniora, Vol.3, No. 1, pp: 215-222.

Williams, B.K. and Sawyer, S.C. 2011. "Using Information Technology: A Practical Introduction to Computers \& Communications. (9th edition)". New York: McGraw-Hill.

Wuryandari, Nur Endah Retno. 2014. Pengaruh Promotion Mix dan Perceived Price Terhadap Visit Intention Serta Implikasinya Terhadap Wilingness To Recommendation (Kajian pada Museum-museum di Kota Bandung). Jurnal Mix, Vol. 4, No.1, hal. 28-41.

Yudhiartika, Dian dan Jony Oktavian Haryanto. 2012. Pengaruh Personal Selling, Display, Promosi Penjualan Terhadap Brand Awareness dan Intensi Membeli pada Produk Kecantikan Pond's. Buletin Studi Ekonomi, Vol.17, No. 2, hal.142-156. 